\title{
A Scoping Review of the Application of the Task-Technology Fit Theory
}

\author{
Ruan Spies $^{1(\mathbb{\otimes})}\left(\mathbb{C}\right.$, Sara Grobbelaar ${ }^{2}$ (I) , and Adele Botha ${ }^{3}(\mathbb{C}$ \\ ${ }^{1}$ Department of Industrial Engineering, Stellenbosch University, Stellenbosch, \\ South Africa \\ 19008953@sun.ac.za \\ 2 Department of Industrial Engineering AND DST-NRF CoE in Scientometrics \\ and Science, Technology and Innovation Policy (sciSTIP), Stellenbosch \\ University, Stellenbosch, South Africa \\ 3 School of Computing, CSIR Meraka \& UNISA, Pretoria, South Africa
}

\begin{abstract}
The Task-Technology Fit (TTF) theory provides a means of quantifying the effectiveness of technology in a system by assessing the relationship between the technology and the tasks the technology aims to support. The theory is widely recognized and has been applied in various ways, but little work has been done to summarize and synthesize the application of TTF in literature. The aim of this study is to identify and summarize the focus areas of studies that applied TTF, the environment in which it was applied, and the technologies which were considered by conducting a scoping review. It was found that applied studies focused primarily on generating theory or assessing certain realworld phenomena; was applied in a wide range of environments with the majority being in healthcare; and considered various technologies, with an increasing number of studies focusing on mobile technology. The findings of this study contribute to the understanding of TTF applications and assists in framing future research to further analyze TTF studies.
\end{abstract}

Keywords: Task-technology fit · Information technology

\section{Introduction}

Technology has become a fundamental aspect of our society and is embedded into everyday life. The way individuals and organizations work and think continues to be shaped by, and shape, various technologies [1]. In an organization, technology is typically applied to generate value by improving or supporting individual and collective tasks but do require a lot of resources for the acquisition, implementation and usage of the various technologies. Therefore, a common question is how much value the technology creates for an organization [2].

Due to the complexity of the interactions between factors such as the technology, users, systems, tasks and process it is extremely difficult to directly measure the value that technology creates in a system $[1,3]$. Alternative measures have therefore been proposed to quantify the impact of technology. One such measure, widely accepted in 
Information System (IS) research [4], is the Task-Technology Fit (TTF) theory which has been suggested to be "one of the most important developments in information system theory" [5]. TTF provides a means to quantify the effectiveness of technology in an organizations [6]. In 2012, Furneaux [7] identified the "notable increase in the use of TTF theory". This trend has continued over the years, with both an increase in the yearly number of documents published as well as in the range of environments which the theory is used, as discussed in this paper.

Despite the wide use of the theory, only two publications by Cane and McCarthy [8] and the work by Furneaux [7] was found that summarizes and synthesizes TTF related studies. The article by Cane and McCarthy [8] is limited to a small number of studies, all of which were conducted before 2006, and only considered how the studies defined TTF and its surrounding components. Furneaux [7] considered a much larger sample of studies where TTF was used, all of which were conducted before 2010, to synthesize the conceptualization, methodologies and research contexts. Where both of the former studies focused primarily on how TTF was applied, this study is concerned with why, where and on what TTF was applied.

The aim of this paper is to conduct a scoping review (SR) aims to explore the application of the Task-technology fit theory by (1) identifying the scope and range of the available literature that applies the specific components of TTF; and (2) summarizing and disseminating the research findings, specifically, (a) the purpose of applying TTF, (b) the environments where TTF has been applied, (c) the technologies that TTF has been applied on. Based on these objectives, the research questions to be answered in this paper are: (1) What are the intentions for applying TTF? (2) Which environments has TTF been applied in? (3) What technologies has TTF been applied on?

\section{Conceptualization of Task-Technology Fit}

In this section, the TTF model, proposed in the seminal article by Goodhue and Thompson [3], is discussed. Goodhue and Thompson [3] states, "Models are ways to structure what we know about reality, to clarify understandings, and to communicate those understandings to others. Once articulated and shared, a model can guide thinking in productive ways, but it can also constrain our thinking into channels consistent with the model, blocking us from seeing part of what is happening in the domain we have modeled."

The basic TTF model, depicted in Fig. 1, therefore provides a lens of technology usage and the value that it creates [3]. In a setting where technology is used by individual's to perform certain tasks, or sets of tasks, the model's premise is that the value/performance of technology is created by the alignment, or fit, of the task requirements and the technology characteristics that allow a user to perform the tasks $[6,9]$.

Tasks refer to the totality of physical and/or cognitive actions and processes done by individuals in a given environment. Task characteristics are considered specifically in relation to the technology that supports the tasks and are broken down to different levels of detail, depending on the complexity of the tasks performed $[3,10]$. 


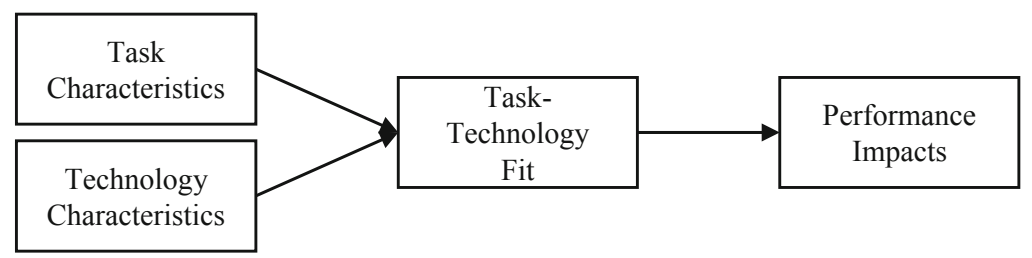

Fig. 1. Basic task-technology fit model

Applying the TTF theory in different environments will result in different specific task characteristics. However, in literature, the process followed to identify the task characteristics are similar and typically involve analyzing the tasks performed in an environment and creating various task categories and subcategories that can be related to TTF $[4,6,11-13]$.

Technology is defined as the tools that are used by individuals to execute, or assist in executing, their tasks $[3,10,14]$. Similar to the discussion of task characteristics, different technologies will have different characteristics which are defined by the researcher with consideration to the environment which it used in and the tasks it aims to support [15].

TTF is defined as the extent to which a technology assists an individual in performing his or her tasks $[3,10,14,16-18]$ and is consequently affected by the interaction between the characteristics of the task and the functionalities of the technology [4]. Typical dimensions that are considered when measuring fit, as defined by Goodhue and Thompson [3], are data quality, data locatability, authorization to access data, data compatibility, ease of use/training, production timeliness, systems reliability, information system relationship with users.

The purpose of the study by Goodhue and Thompson [3] was to show that a positive impact of technology requires a good TTF. Thus, when technology fits the task characteristics it aims to support, it should result in improved performance [9]. The improved performance is typically due to the smooth execution of the task, reducing the cost of performing the task, or making the task easier to accomplish [4].

\section{Methodology}

In 2005, Arksey and O'Malley [19] published the influential article in which it was discussed that there exists ambiguity in the "plethora of terminology" which is used to describe various reviews of literature. The article makes the case that literature review methodologies provide a set of tools which may be used by researchers and that there does not exist an "ideal type" of literature review.

The article argues for SRs to be used to develop an overview of domain knowledge. This is achieved by identifying the quantity of literature and analyzing key features of the literature which differs slightly from traditional systematic reviews which aim to comprehensively synthesize literature. The SR does however follow a similar methodological approach as traditional systematic reviews and can also be considered 
to be replicable and reliable. These features of the SR make it a suitable methodology to answer this study's research questions.

The SR conducted in this study follows the first five stages of the methodology proposed by Arksey and O'Malley [19], namely, to (1) identify the research question; (2) identify relevant studies; (3) select studies; (4) chart the data; (5) collate, summarize and report the results.

The first stage is completed in the Sect. 1 of this study and stages 2-5 are discussed in the following sections and subsections.

\subsection{Search Strategy}

To identify relevant studies that can be used to answer the research questions, a search was conducted on the Scopus research database. Scopus was chosen due to the large number of indexed journals covering a wide range of disciplines. Relevant studies were considered articles published in peer-reviewed journals that apply the TTF theory as part of the primary aim of the study and includes any studies that summarizes work done. In literature, it was found that the term application, in relation to TTF, is used in a broad manner, extending to the use of smaller concepts, adaptations and findings of TTF as part of the studies. In this paper, application (of TTF) is used in a specified manner, to only consider where TTF is used as conceptualized in Sect. 2.

An exploratory search was conducted with the terms "Task-technology fit" OR "technology-to-performance". The titles and abstracts of the top ten cited articles and top ten most recent articles were examined to identify relevant keywords to be included to ensure the comprehensiveness of the search. Variations of the terms evaluate, apply, diagnose and assess were found to be relevant and included in the search. The search was conducted on 04 October 2019 with the search criteria including the terms ("Tasktechnology fit" OR "technology-to-performance") AND (evaluat* OR appl* OR diagnos* OR assess*), limited to journal articles, which yielded 173 results.

Various measures were taken to ensure that all influential articles were included in the study. Bibliometrix, an R-tool for comprehensive science mapping analysis [20], was used to analyze the most cited articles out of the local 173 results, resulting in one article being added. The tool was also used to determine the top locally cited authors. A further search was done on Scopus and ResearchGate to determine whether any further important studies has been published by these authors, resulting in two articles being added. As a final measure, as full-text articles were screened, a list was compiled of the literature each study used as a theoretical foundation. All of the items on the list were however already included and therefore no further studies were added.

\subsection{Study Selection}

The research questions were used to define the inclusion criteria, and inversely the exclusion criteria, as shown in Table 1 . As discussed in the previous section, a large number of studies uses certain concepts of TTF without discussing or applying the theory as conceptualized in Sect. 2, the three exclusion criteria was aimed to specifically eliminate these articles. 
The titles and abstracts of the 176 studies were screened and 43 studies were excluded from the review based on EC 1 . The online availability of the remaining 133 was checked and 5 were found to be unobtainable. The available full-text studies were downloaded, and the data of the studies was exported from Scopus into MS Excel.

Table 1. Inclusion and exclusion criteria

\begin{tabular}{l|l|l|l}
\hline \multicolumn{2}{l|}{ Inclusion criteria } & \multicolumn{2}{l}{ Exclusion criteria } \\
\hline IC 1 & Application of the TTF & EC 1 & No mention of TTF in abstract \\
\hline IC 2 & Thorough discussion of theory & EC 2 & Isolate TTF concepts \\
\hline & & EC 3 & TTF not central to the study \\
\hline
\end{tabular}

The criteria were applied to the abstracts and the full-text articles and 91 studies were excluded due to the content being irrelevant to the study, based on EC 2 and EC 3.

The entire process followed in selecting relevant studies, based on the PRISMA statement for reporting systematic reviews [21], is depicted in Fig. 2.

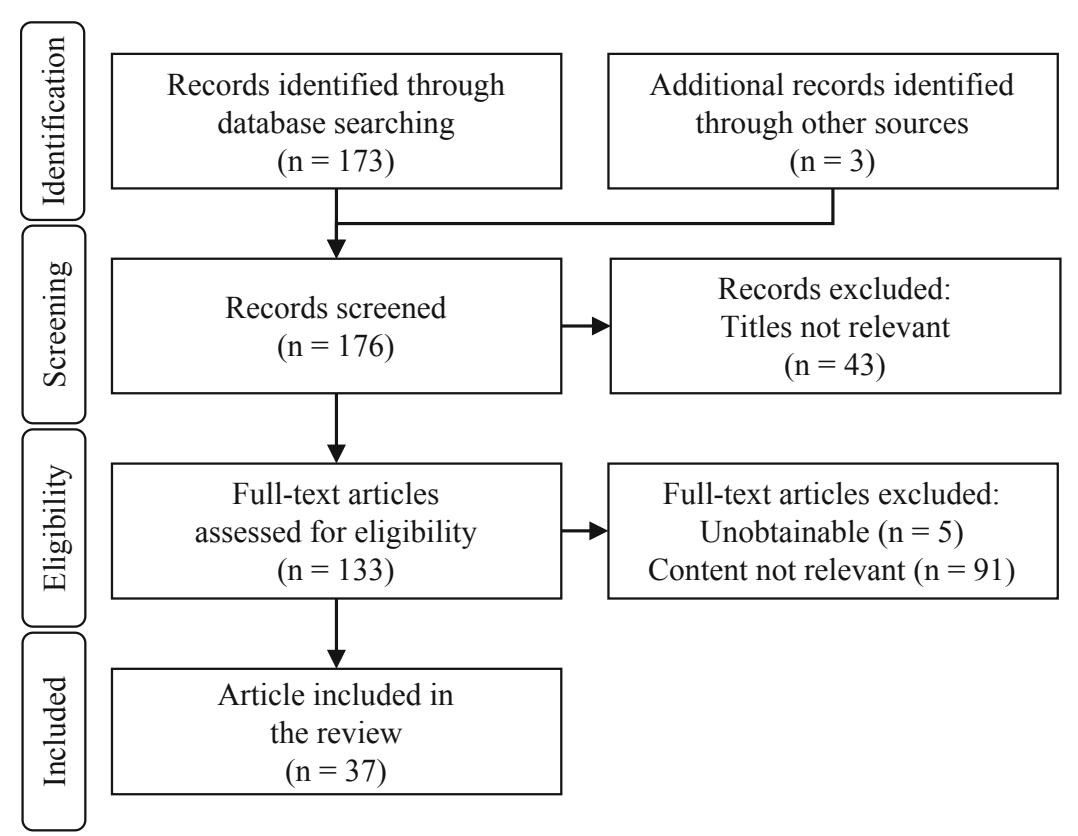

Fig. 2. Study selection process. Adapted from [21].

The study selection process resulted in a total of 37 studies, that applies or discusses TTF as conceptualized in Sect. 2, being included in the review. The process followed to identify and extract the data is discussed in the following section. 


\subsection{Charting the Data}

The charting phases required the articles included in the review to be re-read thoroughly with the aim of extracting the data relevant to the research questions. A charting form was collectively defined by the researchers to ensure credibility of the data to be extracted. The full-text articles were imported into ATLAS.ti, software used for qualitative data analysis and the charting form was used to define the categories for the coding process. The full-text studies were then read through and coded as applicable.

\section{Results}

In this section, the results obtained from analyzing the studies are discussed to answer the research questions.

\subsection{Study Categories}

The coded data, identified as part of the process discussed in Sect. 3.3, was grouped together, and different levels of categories were defined, as depicted in Fig. 3. The first high-level category was defined as studies that apply TTF with the primary aim of generating theory, termed "Generate Theory". The theory generated was found to be primarily concerned with defining or refining the measurements used for the TTF components or the TTF model; summarizing existing studies; testing the components and/or relationships of the TTF model.
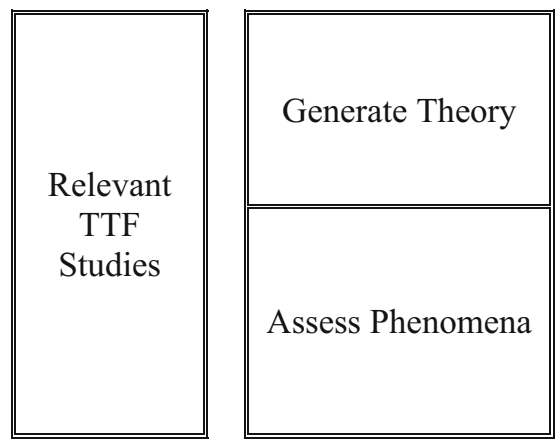

\begin{tabular}{|c|c|}
\hline \multicolumn{2}{|c|}{ Measurements $[6,9,15]$} \\
\hline \multicolumn{2}{|c|}{ Model $[3,17,22-25]$} \\
\hline \multicolumn{2}{|c|}{ Summarize [8] } \\
\hline \multicolumn{2}{|c|}{ Test $[26,27]$} \\
\hline \multicolumn{2}{|c|}{ Antecedents $[5,13,28-31]$} \\
\hline \multirow{2}{*}{ Effects } & $\begin{array}{l}\text { Impact/Benefit } \\
{[32,33,42,34-41]}\end{array}$ \\
\hline & $\begin{array}{l}\text { (Intention to) Use [4, } \\
12,16,43-47]\end{array}$ \\
\hline
\end{tabular}

Fig. 3. Categorization of relevant TTF studies.

The second high-level category was defined as studies that apply TTF in order to assess certain real-world phenomena, termed "Assess Phenomena". These applications were concerned with two major aspects - the components, such as the technology characteristics, that are antecedents to TTF and the assessing effects of TTF. These studies concerned with assessing the effects were further broken down into those that assess the impact or benefit of TTF and those that assess factors relating to the use, or intention to use, of the technology based on TTF. 
The two high level categories were used to determine the trends in the type of studies published over time. The cumulative number of studies published for the two highest-level categories was calculated over time and depicted in Fig. 4. From the figure, it can be seen that a larger number of studies were initially published that aimed to generate theory and that as time progressed the focus shifted to the application of TTF to assess phenomena.

As the theory gained recognition, different aspects of the theory was refined and the impact of applying the theory for assessing different phenomena was recognized, the focus of studies is expected to shift from predominantly theory based to applying it, as seen in the increasing trend in the figure - eventually exponentially overtaking the theoretical.

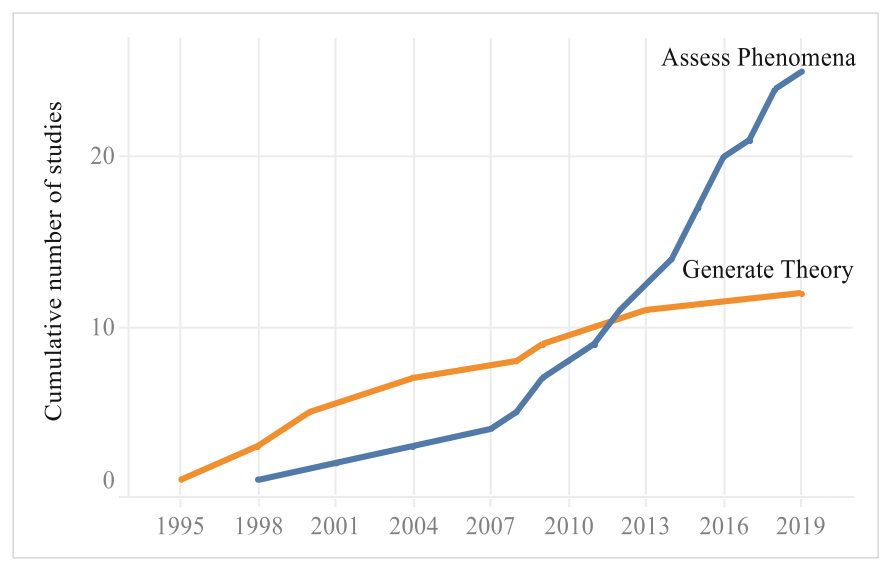

Fig. 4. Cumulative number of studies over time for each study category.

The assessment of TTF antecedents was only introduced in 2009, 11 years after the first application of the theory to assess the impact/benefit and is still an emerging area of research which does hold a lot of potential. Since the antecedents have an effect on TTF, applying the theory to assess these factors has shown to be beneficial in identifying improvements that can be made to ultimately improve TTF.

\subsection{Application Environment}

For each of the relevant studies, the specific environment in which the TTF was applied was identified, collectively categorized by the researchers and is summarized in Fig. 5.

The majority of the studies were applied in either a healthcare setting or in various different, but not explicitly identified, environments. Although the tasks performed in these different environments will vary greatly, the wide range of application environments provides evidence that the TTF can applied in diverse settings. Furthermore, the diverse environments create the opportunity for interesting future research to be done in the similarities and differences in the way in which TTF is applied. 


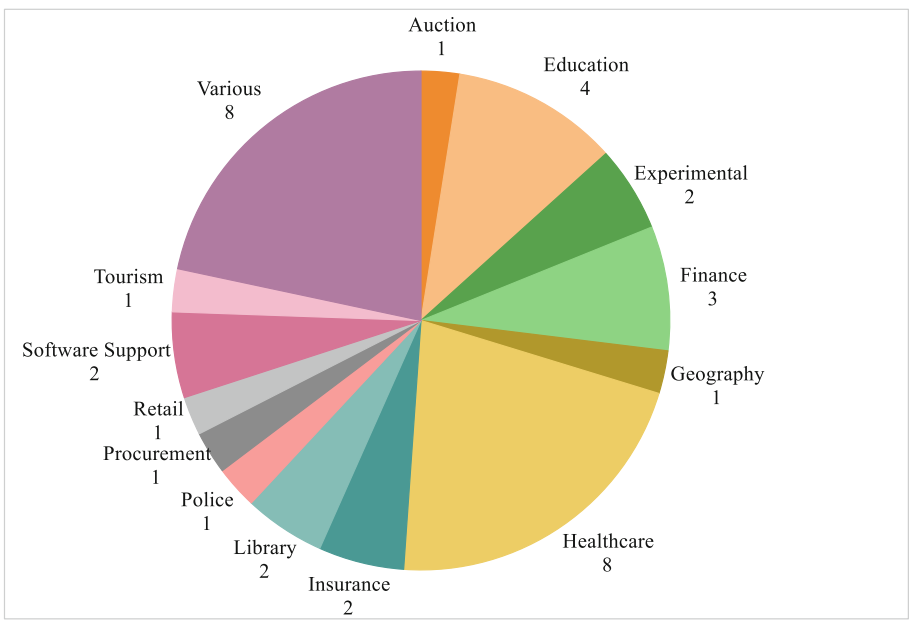

Fig. 5. Divisions of TTF application environments.

\subsection{Assessed Technology}

The technology used in each of the relevant studies was also identified, collectively categorized by the researchers and is summarized in Fig. 6.

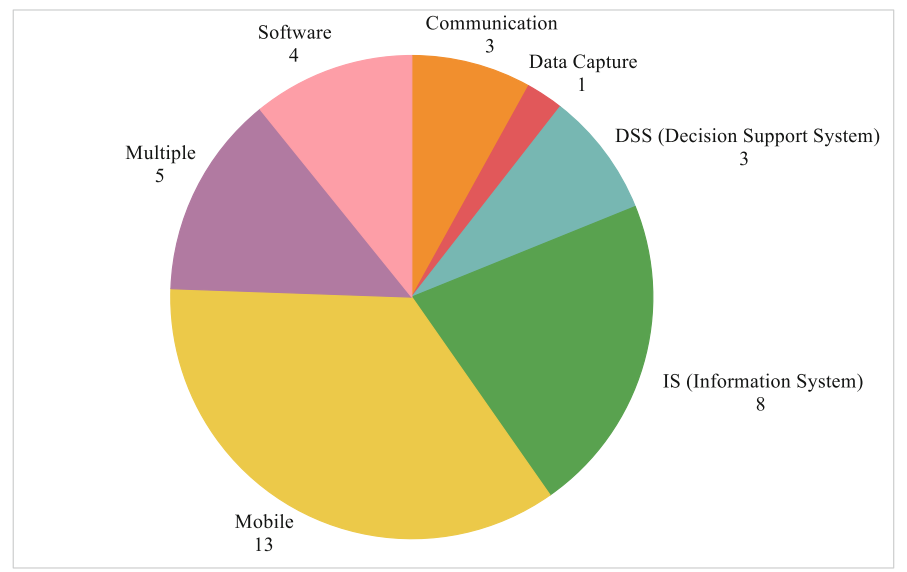

Fig. 6. Divisions of the technology assessed in the relevant studies.

Since the TTF theory is mainly part of IS research, it was expected that the application of TTF would primarily be concerned with IS. An interesting observation was the growing research interest in mobile technology. The first two relevant studies applying TTF to mobile technology [15, 36] was published in 2004 after which the majority of future published articles included in this study (40.7\%) was focused on 
mobile technology. This finding makes sense in considering the rapid uptake, improved capabilities and gradual dependence on smartphone technology since 2004.

\section{Conclusion}

The TTF theory has been an important development in IS research and has been widely applied in various environments and on a range of technologies. This study aimed to identify and analyze relevant literature that applies the specific components of TTF to answer three research questions concerned with why, where and on what TTF was applied.

As part of the chosen SR methodology, a structured search and screening approach was followed to identify relevant studies, the detailed discussion on the process followed ensuring the reliability and replicability thereof. These studies were then analyzed, the data extracted, and the findings synthesized to answer the research questions. The implementation and discussion of the methodology ensured the validity and reliability of the study.

The first research question is answered in the analysis and synthesis of the intentions for applying TTF where various levels of categories were defined for the intentions. The categories were further used to determine specific trends over time, revealing how the focus of studies shifted from predominantly theory based to the application of TTF to assess various phenomena.

The analysis and synthesis of the application environment and assessed technology revealed the wide range of environments and technologies associated with the application of TTF, consequently answering both the second and final research questions. These findings reveal the wide range of applicability of the TTF theory and also the potential that it holds for both industry and academia in applying TTF in different environments and with new technologies.

The results of the scoping review are dependent on the studies included for analysis. The initial search for relevant articles is limited in that only one database was used to search for relevant articles. This may have resulted in further relevant works being excluded from this study. Various measures were however taken to ensure that all influential studies potentially missed in the search were included in this study. Although the intention was to define screening criteria in a manner that would ensure reliability and replicability of the screening process, the authors acknowledge that

Despite the limitations of the study, the findings of this study are valuable and further assists in framing future research on the application of TTF. The different studies which apply TTF may be further analyzed to determine trends in the methodologies followed within and/or across the different application categories, environments and technologies. This in turn may be used to provide guidelines in the quantitative measurement of different TTF constructs, given a specific intention for, and context of, use. The suggested future research may assist in the classic pursuit to better understand, account for and explain the impact of technologies within a system. 


\section{References}

1. Orlikowski, W.J.: Using technology and constituting structures: a practice lens for studying technology in organizations. Organ. Sci. 11, 404-428 (2000). https://doi.org/10.1287/orsc. 11.4.404.14600

2. Melville, B.N., Kraemer, K.: Review: information technology and organizational performance. MIS Q. 28, 283-322 (2004)

3. Goodhue, D.L., Thompson, R.L.: Task-technology fit and individual performance. MIS Q. Manag. Inf. Syst. 19, 213-233 (1995)

4. Lee, C.C., Cheng, H.K.H.H.: An empirical study of mobile commerce in insurance industry: task-technology fit and individual differences. Decis. Support Syst. 43, 95-110 (2007). https://doi.org/10.1016/j.dss.2005.05.008

5. Melchor-Ferrer, E., Buendía-Carrillo, D.: Financial information management for university departments, using open-source software. Int. J. Inf. Manag. 34, 191-199 (2014). https://doi. org/10.1016/j.ijinfomgt.2013.12.009

6. Goodhue, D.L.: Development and measurement validity of a task-technology fit instrument for user evaluations of information system. Decis. Sci. 29, 105-138 (1998). https://doi.org/ 10.1111/j.1540-5915.1998.tb01346.x

7. Furneaux, B.: Task-technology fit theory - a survey and synopsis of the literature.pdf. In: Information Systems Theory Integrated Series in Information Systems, pp. 87-106 (2012)

8. Cane, S., McCarthy, R.: Analyzing the factors that affect information systems use: a tasktechnology fit meta-analysis. J. Comput. Inf. Syst. 50, 108-123 (2009)

9. Goodhue, D.L., Klein, B.D., March, S.T.: User evaluations of IS as surrogates for objective performance. Inf. Manag. 38, 87-101 (2000). https://doi.org/10.1016/S0378-7206(00) 00057-4

10. Ammenwerth, E., Iller, C., Mahler, C.: IT-adoption and the interaction of task, technology and individuals: a fit framework and a case study. BMC Med. Inform. Decis. Mak. 6, 1-13 (2006). https://doi.org/10.1186/1472-6947-6-3

11. Barki, H., Titah, R., Boffo, C.: System use-related activity: an behavioral conceptualization of expanded information system use. Inf. Syst. Res. 18, 173-192 (2007). https://doi.org/10. 1287/isre.1070.0122

12. Wang, S.L., Lin, H.I.: Integrating TTF and IDT to evaluate user intention of big data analytics in mobile cloud healthcare system. Behav. Inf. Technol. 3001, 974-985 (2019). https://doi.org/10.1080/0144929X.2019.1626486

13. Ali, S.B., Romero, J., Morrison, K., Hafeez, B., Ancker, J.S.: Focus section health IT usability: applying a task-technology fit model to adapt an electronic patient portal for patient work. Appl. Clin. Inform. 9, 174-184 (2018). https://doi.org/10.1055/s-00381632396

14. Yang, L., Yang, S.H., Plotnick, L.: How the internet of things technology enhances emergency response operations. Technol. Forecast. Soc. Change 80, 1854-1867 (2013). https://doi.org/10.1016/j.techfore.2012.07.011

15. Gebauer, J., Shaw, M.J.: Success factors and impacts of mobile business applications: results from a mobile e-procurement study. Int. J. Electron. Commer. 8, 19-41 (2004). https://doi. org/10.1080/10864415.2004.11044304

16. Dishaw, M.T., Strong, D.M.: Assessing software maintenance tool utilization using tasktechnology fit and fitness-for-use models. J. Softw. Maint. Evol. 10, 151-179 (1998)

17. Howard, M.C., Rose, J.C.: Refining and extending task-technology fit theory: creation of two task-technology fit scales and empirical clarification of the construct. Inf. Manag. 56, 103134 (2018). https://doi.org/10.1016/j.im.2018.12.002 
18. Fuller, R.M., Dennis, A.R.: Does fit matter? The impact of task-technology fit and appropriation on team performance in repeated tasks. Inf. Syst. Res. 20, 2-17 (2009). https:// doi.org/10.1287/isre.1070.0167

19. Arksey, H., O’Malley, L.: Scoping studies: towards a methodological framework. Int. J. Soc. Res. Methodol. 8, 19-32 (2005). https://doi.org/10.1017/s0922156508005621

20. Aria, M., Cuccurullo, C.: bibliometrix: an R-tool for comprehensive science mapping analysis. J. Informetr. 11, 959-975 (2017)

21. Moher, D., Liberati, A., Tetzlaff, J., Altman, D.G., PRISMA Group: Preferred reporting items for systematic reviews and meta-analyses: the PRISMA statement. PLOS Med. 6, 1-6 (2009). https://doi.org/10.1371/journal.pmed.1000097

22. Dishaw, M.T., Strong, D.M.: Supporting software maintenance with software engineering tools: a computed task-technology fit analysis. J. Syst. Softw. 44, 107-120 (1998). https:// doi.org/10.1016/S0164-1212(98)10048-1

23. Gebauer, J., Tang, Y.: Applying the theory of task-technology fit to mobile technology: the role of user mobility. Int. J. Mob. Commun. 6, 321-344 (2008). https://doi.org/10.1504/ IJMC.2008.017514

24. Liu, Y., Lee, Y., Chen, A.N.K.: Evaluating the effects of task-individual-technology fit in multi-DSS models context: a two-phase view. Decis. Support Syst. 51, 688-700 (2011). https://doi.org/10.1016/j.dss.2011.03.009

25. Yang, H.D., Kang, S., Oh, W., Kim, M.S.: Are all fits created equal? A nonlinear perspective on task-technology fit. J. Assoc. Inf. Syst. 14, 694-721 (2013)

26. Staples, D.S., Seddon, P.B.: Testing the technology-to-performance chain model. Adv. Top. End User Comput. 4, 42-64 (2005). https://doi.org/10.4018/978-1-59140-474-3.ch003

27. Zigurs, I., Buckland, B.K., Connolly, J.R., Vance Wilson, E.: A test of task-technology fit theory for group support systems. Data Base Adv. Inf. Syst. 30, 34-50 (1999). https://doi. org/10.1145/344241.344244

28. Gebauer, J., Ginsburg, M.: Exploring the black box of task-technology fit. Commun. ACM 52, 130-135 (2009). https://doi.org/10.1145/1435417.1435447

29. Hsiao, J., Chen, R.-F.: An investigation on fit of mobile nursing information systems for nursing performance. CIN - Comput. Inform. Nurs. 30, 265-273 (2012). https://doi.org/10. 1097/NCN.0b013e31823eb82c

30. Pelzer, P., Arciniegas, G., Geertman, S., Lenferink, S.: Planning support systems and tasktechnology fit: a comparative case study. Appl. Spat. Anal. Policy 8, 155-175 (2015). https://doi.org/10.1007/s12061-015-9135-5

31. Rivera, M., Croes, R., Zhong, Y.S.: Developing mobile services: a look at first-time and repeat visitors in a small island destination. Int. J. Contemp. Hosp. Manag. 28, 2721-2747 (2016). https://doi.org/10.1108/IJCHM-02-2015-0052

32. Bere, A.: Applying an extended task-technology fit for establishing determinants of mobile learning: an instant messaging initiative. J. Inf. Syst. Educ. 29, 239-252 (2018)

33. Cady, R.G., Finkelstein, S.M.: Task-technology fit of video telehealth for nurses in an outpatient clinic setting. Telemed. e-Health 20, 633-639 (2014). https://doi.org/10.1089/tmj. 2013.0242

34. Chen, P., Yu, C., Chen, G.Y.: Applying task-technology fit model to the healthcare sector: a case study of hospitals' computed tomography patient-referral mechanism. J. Med. Syst. 39 (2015). https://doi.org/10.1007/s10916-015-0264-9

35. Glowalla, P., Sunyaev, A.: ERP system fit - an explorative task and data quality perspective. J. Enterp. Inf. Manag. 27, 668-686 (2014). https://doi.org/10.1108/JEIM-08-2013-0062

36. Ioimo, R.E., Aronson, J.E.: Police field mobile computing: applying the theory of tasktechnology fit. Police Q. 7, 403-428 (2004). https://doi.org/10.1177/1098611103251113 
37. Kim, D.-Y., Han, S.-M., Youngblood Jr., M.: Sequential patient recruitment monitoring in multi-center clinical trials. Commun. Stat. Appl. Methods 25, 501-512 (2018). https://doi. org/10.29220/CSAM.2018.25.5.501

38. McGill, T.J., Klobas, J.E.: A task-technology fit view of learning management system impact. Comput. Educ. 52, 496-508 (2009). https://doi.org/10.1016/j.compedu.2008.10.002

39. Raven, A., Le, E., Park, C.: Digital video presentation and student performance: a task technology fit perspective. Int. J. Inf. Commun. Technol. Educ. 6, 17-29 (2010). https://doi. org/10.4018/jicte.2010091102

40. Tam, C., Oliveira, T.: Understanding the impact of m-banking on individual performance: DeLone \& McLean and TTF perspective. Comput. Human Behav. 61, 233-244 (2016). https://doi.org/10.1016/j.chb.2016.03.016

41. Yi, Y.J., You, S., Bae, B.J.: The influence of smartphones on academic performance: the development of the technology-to-performance chain model. Libr. Hi Tech 34, 480-499 (2016). https://doi.org/10.1108/LHT-04-2016-0038

42. Lepanto, L., Sicotte, C., Lehoux, P.: Assessing task-technology fit in a PACS upgrade: do users' and developers' appraisals converge? J. Digit. Imaging 24, 951-958 (2011). https:// doi.org/10.1007/s10278-011-9378-x

43. Vongjaturapat, S.: Application of the task-technology fit model to structure and evaluation of the adoption of smartphones for online library systems. Sci. Technol. Asia 23, 39-56 (2018). https://doi.org/10.14456/scitechasia.2018.6

44. Chang, H.H.: Intelligent agent's technology characteristics applied to online auctions' task: a combined model of TTF and TAM. Technovation 28, 564-577 (2008). https://doi.org/10. 1016/j.technovation.2008.03.006

45. Huang, L., Shiau, W.-L.W., Lin, Y.: What factors satisfy e-book store customers? Development of a model to evaluate e-book user behavior and satisfaction. Internet Res. 27, 563-585 (2017). https://doi.org/10.1108/IntR-05-2016-0142

46. Pendharkar, P.C., Khosrowpour, M., Rodger, J.A.: Development and testing of an instrument for measuring the user evaluations of information technology in health care. J. Comput. Inf. Syst. 41, 84-89 (2001)

47. Sheehan, B., Lee, Y., Rodriguez, M., Tiase, V., Schnall, R.: A comparison of usability factors of four mobile devices for accessing healthcare information by adolescents. Appl. Clin. Inform. 3, 356-366 (2012). https://doi.org/10.4338/ACI-2012-06-RA-0021 